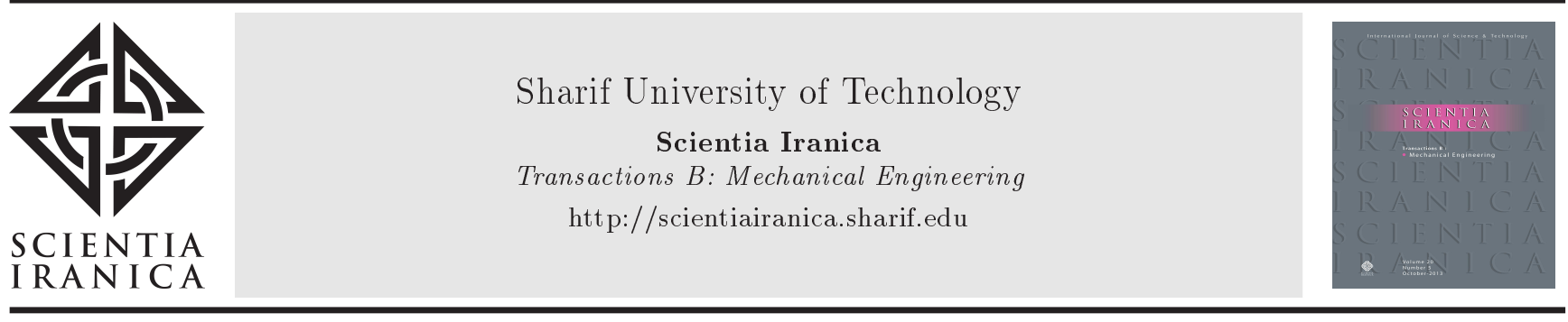

\title{
Performance evaluation of aluminium oxide nano particles in cutting fluid with minimum quantity lubrication technique in turning of hardened AISI 4340 alloy steel
}

\author{
A. Das ${ }^{\mathrm{a}, *}$, S.K. Patel ${ }^{\mathrm{b}}$, B.B. Biswal ${ }^{\mathrm{a}}$, and S.R. Das ${ }^{\mathrm{c}}$ \\ a. Department of Industrial Design, National Institute of Technology, Rourkela 769008, Odisha, India. \\ b. Department of Mechanical Engineering, National Institute of Technology, Rourkela 769008, Odisha, India. \\ c. Department of Production Engineering, Veer Surendra Sai University of Technology, Burla 768018, Odisha, India.
}

Received 10 June 2018; received in revised form 10 January 2019; accepted 21 July 2019

\section{KEYWORDS}

AISI 4340;

Cermet inserts;

MQL;

Nanofluid;

Machinability.

\begin{abstract}
The current research comprises various machinability aspects of 4340 hardened alloy steel which are scrutinized in the context of improvements in main cutting force, tool flank wear, crater wear, surface roughness, microhardness, machined surface morphology, chip morphology, chip reduction coefficient and apparent coefficient of friction under three different cutting fluid applications, i.e. compressed air, water soluble coolant based Minimum Quantity Lubrication (MQL), and a nanofluid (using eco-friendly radiator coolant as the base fluid and $\mathrm{Al}_{2} \mathrm{O}_{3}$ as the nanoparticle) based MQL technique using cermet cutting inserts. A comparative assessment was performed to select which fluid performed better in terms of machining attributes between three cutting fluids. A MQL technique was used in which a smaller volume of coolant was sprinkled at high pressure. This method is found to be the most effective alternative to minimize health risks and machining costs, which are quite high in other setups. The test specimen was machined at three different cutting speeds i.e. 100, 120, and $140 \mathrm{~m} / \mathrm{min}$ along with two machining parameters i.e. feed and depth of cut, which were kept constant, respectively, at $0.2 \mathrm{~mm} / \mathrm{rev}$ and $0.4 \mathrm{~mm}$. Outcomes made a conclusion that $\mathrm{Al}_{2} \mathrm{O}_{3}$ enriched ecofriendly nano-coolant outperformed both compressed air and water soluble coolant in terms of every machinability aspect.
\end{abstract}

(C) 2020 Sharif University of Technology. All rights reserved.

\section{Introduction}

The production industry is being equipped with newer advancements in modern technology every day. To sustain and grow in this competitive era, new implicative researches are becoming extremely necessary to produce furnished products without disturbing ecological harmony and keeping production costs in check. Hence,

*. Corresponding author.

E-mail address: anshuman.das2009@gmail.com (A.Das)

doi: $10.24200 /$ sci.2019.51223.2069 effective alternatives are required. One such focused area in the manufacturing domain is hard turning which is derived from the fundamental "turning" operation. It is a single point cutting process usually effective for those materials having a hardness magnitude of more than 45 HRC. The workpiece can be reduced to its final shape in the hardened state during hard turning. Hard turning was found to be a better alternative to cylindrical grinding after adequate exploration, as the set up was time reduced, process flexibility enhanced, production costs lowered and finishing was almost equivalent to that of grinding. But non-favorable situations always pop-up such as a high degree of heat 
dissipation which requires expensive high performance cutting tools and extremely rigid machine tools. There are various machinability aspects through which the quality of the finished products can be controlled such as surface roughness, machining forces and tool life [1]. Heat generation is an undesired natural phenomenon for any machining operation. It generates at various zones during metal cutting, basically in tool-work and tool-chip interfaces. Heat reduction is tremendously essential as it affects different machinability aspects. So, for the reduction of heat and the enhancement of machinability aspects, newer metal working fluids are used numerously by various industries. Generally, cutting fluids in machining process are used to:

1. Reduce frictional force at contact areas;

2. Cool both cutting tool and workpiece;

3. Help to remove chips from the material removal region.

Various metalworking fluid delivery techniques are implemented. The most common is flood cooling. In this technique, the coolant comes out through the nozzle with a greater flow rate but a messy environment increases the health risk factor and time consuming clean up reduces its application. Cost is another constraint. Thus, proposing new environmental cooling and lubricant systems is highly required especially to improve cutting quality characteristics and achieve a sustainable machining system. The modern approach to machining places an emphasis on the elimination or minimization of the use of lubricant fluid during the machining process due to environmental aspects. This approach is based on optimized cutting fluid application methods (e.g. high pressure coolant, Minimum Quantity Lubrication (MQL), and nanofluid based MQL) [2]. Based on the research results, using advanced techniques in cutting fluid application (such as MQL) in the machining process leads to a reduction in cutting forces and heat rejection in cutting regions and improves the durability of the cutting tool and surface finish of the workpiece; however, the excessive heat generation problem has not been completely solved. Proposing new nano-cutting fluids can contribute in facing the heat dissipation challenge during cutting processes as it offers a higher observed thermal conductivity value in comparison with the base lubricants. Additionally, it is shown that nano-cutting fluids have superior cooling properties due to their good heat extraction capabilities [3].

Kuzu et al. [4] experimentally investigated chip morphology and the machinability of compacted graphite iron in plain turning under dry and MQL conditions. They have concluded that MQL resulted in a lower friction coefficient and provided a reduction in cutting force along withsurface roughness by 2-
$5 \%$ and $25 \%$, respectively, in comparison to a dry finish turning condition. Amini et al. [5] investigated how near dry machining can be improved and also studied the effect on tool wear in the turning of AISI 4142 alloy steel. From the experiments, they found that tool life in near dry machining was longer than that in dry machining. Further, it showed a positive impact on surface roughness, which meant that higher cutting speeds could be used by the MQL method compared to the dry machining method. Kumar et al. [6] reported that high latent heat absorbed by water droplets during evaporation through the spray impingement cooling technique (similar to the MQL technique), reduces cutting temperature and thus reduces the evolution of tool wear and induces an environmentally friendly cleaner machining. Mia et al. [7] experimentally investigated the effect of different cooling-lubrication conditions (Dry Cutting condition DC, Conventional flood cooling, FC, Minimum Quantity Lubrication condition MQL, and Solid Lubrication mixed with Compressed Air cooling condition SL+CA) on prominent machining indices (cutting temperature, surface roughness, chip characteristics, and tool wear) in hard turning AISI 1060 steel. Consequently, the Pugh matrix environmental approach has been used to establish the sustainability assessment model (in terms of environmental effect, operator health, coolant cost, recycling cost and disposal, part cleaning, and selected machining responses) among the aforementioned cooling-lubrication conditions. Their research findings show that the MQL system can ameliorate the heat transfer problem and shows quite promising results in improvement of the desirable machinability characteristics, including environmental friendliness as well as cleaner production. In another study with similar workpiece materials, Mia et al. [8] used the Grey-Taguchi method for multi-objective optimization of tool-chip interaction parameters (chip compression ratio, effective shear angle, friction coefficient at tool rake surface and chip-tool interface temperature) under two sustainable cutting conditions, i.e., dry and MQL. Later, Mia et al. [9] applied a Least-Square Support Vector Machine (LS-SVM) followed by an Interior Point Method (IPM) for prediction and optimization of surface roughness.

Nemati et al. [10] reported that by the addition of nanoparticles to fluid, the Nusselt number increases, thereby resulting in conduction as being significant for the heat transfer mechanism rather than convection. Amrita et al. [11] made a performance evaluation of nano graphite inclusions in the MQL technique in the turning of AISI 1040 steel. Due to the inclusion of nano graphite, reductions in surface roughness, tool flank wear, temperature and cutting forces were observed. Sharma et al. [12] reviewed the research work of many researchers in the field of nano-cutting fluid 
and found that the addition of nanoparticles into the base fluid enhances its thermal conductivity, which in turn, improves surface quality, tool life and reduces the cutting force and cutting temperature. It has been found that inclusion of graphite nanoparticles into conventional lubricants enhances its tribological property due to the reduced coefficient of friction. Because of their low friction behavior, graphite and MoS2 solid lubricants reduced surface roughness and cutting force during machining. During the hard turning of high-carbon-high-chromium AISI D2 steel (66 HRC) with the nanofluid based minimum quantity lubrication (NFMQL) technique, Sharma et al. [13] investigated the effect of Multi Wall Carbon Nano Tubes (MWCNT) on cutting temperature as well as surface roughness They concluded a tremendous improvement in surface finish as well as quality in the machined part, along with, reduction of the cutting zone temperature due to the inclusion of MWCNT nanoparticles in the cutting fluid leading to lesser tool wear. Su et al. [14] evaluated the performance of graphite based nanofluid using vegetable based oil or ester oil in cylindrical turning of AISI 1045 steel and the thermo-physical properties like viscosity, surface tension, wettability, thermal conductivity were measured. It was observed that cutting force and temperature were reduced significantly when nanofluid was used. Potole and Kulkarni [15] applied nanofluids in longitudinal plain turning, of AISI 4340 grade HSLA steel by the MQL technique for experimental investigation and multi response optimization. Furthermore, comparative analysis was made to evaluate the cutting performance of MWCNT nanoparticles mixed with two different base fluids such as ethylene and water. Results showed that MWCNT nanoparticles mixed with base fluids as ethylene gives better surface roughness as compared to other lubrication systems due to better heat carrying capacity. Similarly, Khajehzadeh et al. [16] studied the effect of $\mathrm{TiO}_{2}$ nanoparticles' size and concentration on contact length during hard turning of AISI 4140 steel using experimental as well as numerical methods. Based on their results, $\mathrm{TiO}_{2}$ nanoparticles in nanofluid are able to decrease tool-chip contact length, cutting forces and friction coefficient as compared to dry machining. Amrita et al. [17] investigated the application of emulsifier oil based nano cutting fluids in metal cutting process and found that performance of the cutting fluid was measured by various factors like cutting forces, cutting temperature near the chip tool interface, tool wear and surface roughness for each turn. In hard turning of AISI 304 stainless steel, Sharma et al. [18] investigated the machining performance of alumina- $\mathrm{MoS}_{2}$ mixed hybrid nanofluid and alumina-graphite hybrid nano-cutting fluid [19] using the MQL technique. In comparison to $\mathrm{Al}_{2} \mathrm{O}_{3}$ mixed nano-cutting fluid, the alumina- $\mathrm{MoS}_{2}$ hybrid nano-cutting fluids have shown a significant reduction of $7.35 \%, 18.08 \%, 5.73 \%$, and $2.38 \%$, respectively in cutting force, feed force, thrust force and surface roughness whilethe application of alumina-graphite hybrid nanofluid using the MQL technique reduced the abovementioned response by $9.94 \%, 7.25 \%, 17.38 \%$, and $20.28 \%$, respectively.

Based on the literature review and to the best of the author's knowledge, until now, the research application of eco-friendly radiator coolant based nanocutting fluid in hand turning processes has not yet been reported. Furthermore, the literature does not reveal the presence of any article systematically describing machinability assessment during the hard turning of AISI 4340 steel under dry, MQL, and NFMQL conditions, respectively. Being comparatively new, this combination of cooling-lubrication techniques has not yet been studied in hard turning. From the above mentioned published works, the performance of cermet inserts under cutting conditions (aluminum oxide nanoparticle into radiator coolant) using the MQL technique in the context of sustainable and clean manufacturing is still inadequate to offer a holistic understanding of the process performance. In consideration of the aforementioned research gap, the aim of the present experimental work is to evaluate the performance of different cutting fluids including $\mathrm{Al}_{2} \mathrm{O}_{3}$ nanoparticles based coolant in the hard turning of AISI 4340 alloy steel in terms of main cutting force, tool flank wear, crater wear, surface roughness, microhardness, machined surface morphology, chip morphology, chip reduction coefficient and the apparent coefficient of friction using cermet inserts. The present study deals with a vast area of knowledge about the application of different cooling-lubrication methods in the finish of the hard turning process where the problem of chip control and cutting tool wear play a very important role in the enhancement of machining performance as well as improvement of machinability.

\section{Experimental details}

In the present experimental work, three different cutting fluids were used i.e. compressed air, water soluble coolant and $\mathrm{Al}_{2} \mathrm{O}_{3}$ based nanofluid, and machinability aspects were evaluated for hardened alloy steel (AISI 4340) using the MQL technique. Three different levels of industrially implemented cutting speed were considered whereas feed rate and depth of cut were kept unaltered. The tool used was uncoated cermet insert. Machinability aspects, especially cutting force, tool flank wear, crater wear, surface roughness, microhardness, machined surface morphology, morphology of the chip surface, coefficient of chip contraction and apparent coefficient of friction, were evaluated for each case and a comparative assessment was performed 
between them. The experimental runs were carried out at three speed levels i.e. 100,120 and $140 \mathrm{~m} / \mathrm{min}$ for the machining time of 30,60,90,120, 180 and $240 \mathrm{~s}$. Feed and depth of cut were fixed at $0.2 \mathrm{~mm} / \mathrm{rev}$ and $0.4 \mathrm{~mm}$, respectively.

Three cutting forces in three mutually perpendicular directions; axial, tangential and radial, were measured using a three dimensional dynamometer (Manufactured by Kistler, Switzerland). Each component was measured thrice for error minimization and then the principal cutting force $(\mathrm{Fc})$ was evaluated for thorough analysis. To measure the surface roughness of the machined part, a Taylor Hobson roughness tester (Model: Surtronic 3+) was used. Four locations were chosen and roughness was measured around the machined specimen circumference. The procedure was repeated thrice and the average value was finally considered as mean value. Both the flank wear and crater wear of the inserts were measured using an advanced optical microscope (Manufactured by Carl Zeiss, Model: Axio Cam ERc 5 s). A Scanning Electron Microscope (SEM) was used at flank and rake faces for better morphological analysis. On the worn out faces, i.e. both rake and flank faces of inserts, wear was quantified at three divergent positions for better accuracy and their mean values were treated as final for further analyses. Machined surface morphology for three cutting conditions was analyzed using SEM. The chip morphology was examined using both SEM and photographic images. Chip thickness was measured using a vernier caliper at five different locations and the mean value was considered as final. Samples were cut from the machined surface for microhardness analysis and mounted thereafter. Each sample was polished after mounting with different grades of polishing papers. A Vickers micro hardness tester (Manufactured by Leco, Model: LM248AT) was used to obtain the microhardness of the machined samples in all three cutting environments. The microhardness measurements were performed in the sub-surface region of the test specimen along a straight line perpendicular to the machined surface (radially). A gap of $10 \mathrm{\Delta m}$ was kept between two consecutive indentations. $10 \mathrm{~s}$ and $0.025 \mathrm{~N}$ were set as the dwell time and test load respectively.

\subsection{Test specimen}

AISI 4340 alloy steel was chosen to be the test specimen for this present experimental investigation, having diameter $50 \mathrm{~mm}$ and length $700 \mathrm{~mm}$. It was a medium carbon low alloy steel consisting of chromium, nickel and molybdenum. Molybdenum prevents the steel from temper embrittlement. This specimen is characterized by low specific heat, excessive hardness and high strain hardening. It has better impact resistance, as well as wear and abrasion resistance, in
Table 1. Composition of AISI 4340 steel.

\begin{tabular}{lc}
\hline \multicolumn{1}{c}{ Element } & Weight (\%) \\
\hline Nickel, Ni & 1.550 \\
Chromium, Cr & 0.900 \\
Manganese, Mn & 0.770 \\
Carbon, C & 0.397 \\
Molybdenum, Mo & 0.275 \\
Silicon, Si & 0.339 \\
\hline
\end{tabular}

the hardened condition. It has high ductility under annealed conditions. This alloy is extensively used in the manufacturing of power transmission gears and shafts, aircraft landing gears, automotive, oil and gas drilling etc. The chemical composition of the AISI 4340 was tested using a Spectrometal analyzer, and the result is shown in Table 1.

The experiment was performed on a heavy duty conventional lathe machine. The maker of this machine was Hindustan Machine Tools (HMT) Ltd., Bangalore, India and the model was NH26.

\subsection{Heat treatment}

Heat treatment becomes essential when microstructural alterations and sometimes the chemical properties of a specimen are required to be changed. It is a complex process initiated by treating the sample to an austenizing temperature of $920^{\circ} \mathrm{C}$. The workpiece was kept at that temperature for 30 minutes thereafter to allow the reformation of crystalline structures. Then, oil quenching was accomplished as this alloy's hardenability was suited for this quenching process only. Subsequently, the sample was heated to a temperature below critical i.e. $400^{\circ} \mathrm{C}$ for tempering, and kept in a similar condition for 2 hours. The salient feature of this process was to reduce the hardness in the material and enhance toughness. This was followed by gradual cooling of the workpiece in atmospheric conditions to avoid any residual stress and hence a homogenous structure was formed. Through this process, there was an enhancement of hardness from 18 HRC to 48 HRC. After the heat treatment process, the martensite and ferrite structure was formed, as shown in Figure 1.

\subsection{Selection of cutting insert and tool holder}

Here, an uncoated cermet insert was chosen for the experiment. A cermet consists of a ceramic material dispersed in a metal matrix. The ceramic quotient helps to provide wear resistance and the metal quotient enhances toughness. The advantage of using this insert is that it provides superior resistance to thermal and mechanical fracture, reducing machining costs. The designation of this cermet was SNMG 120408. The grade of the tool was NS730, manufactured by the 


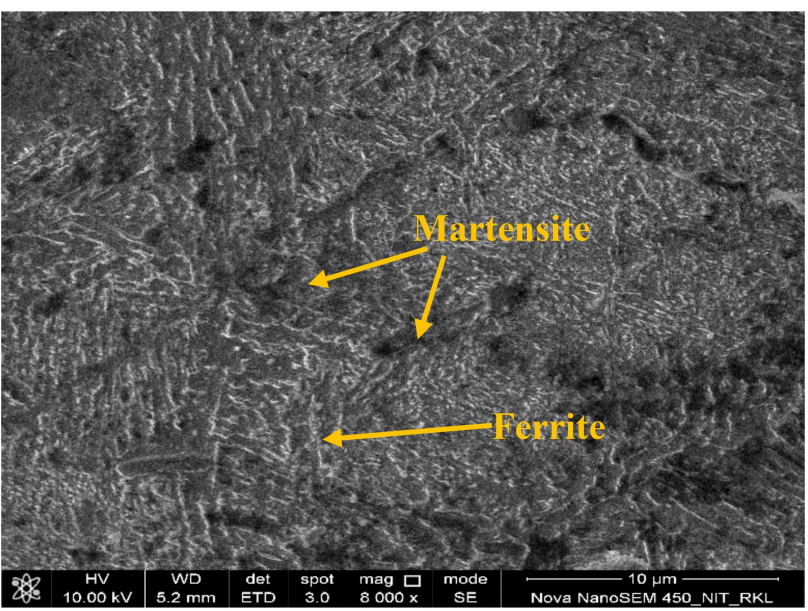

Figure 1. Microstructure of hardened steel after heat treatment.

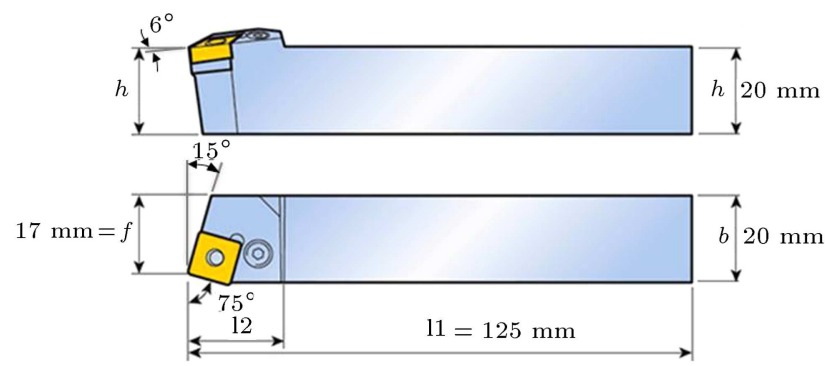

Figure 2. Illustration of cutting geometry of tool holder.

Table 2. Property of the insert.

\begin{tabular}{ccc}
\hline $\begin{array}{c}\text { Specific } \\
\text { gravity }\end{array}$ & $\begin{array}{c}\text { Hardness } \\
\text { in HRA }\end{array}$ & $\begin{array}{c}\text { Transverse rupture } \\
\text { strength in GPa }\end{array}$ \\
\hline 6.8 & 92 & 2.2 \\
\hline
\end{tabular}

Tungaloy Corporation. The designation of the tool holder was PSBNR 2020K12. Some of the properties of the insert are given in Table 2, shown below. The detailed cutting geometries of the tool holder are illustrated in Figure 2. The nomenclature of the inserts is very important to understand its geometry. Table 3 given below describes the tool geometry in detail.

\subsection{Selection and preparation of cutting fluids}

As discussed earlier, three types of cutting fluids were selected i.e. compressed air, water soluble coolant and $\mathrm{Al}_{2} \mathrm{O}_{3}$ nanoparticle based cutting fluid. First, compressed air was used as the cutting fluid and it was supplied at 7 bar pressure and a flow rate of $150 \mathrm{ml} / \mathrm{h}$ to the machining zone. For the second phase of experimental run, a water soluble coolant was used. Servo cut metal working fluid was selected for the experiment. The coolant was prepared by intermixing water (base fluid) in the ratio of 10:1. Nanofluid was used in the last phase of the experiment, which was a homogenous mixture of aluminium oxide nanoparticles
Table 3. Nomenclature of cutting inserts.

\begin{tabular}{cl}
\hline Abbreviation & \multicolumn{1}{c}{ Details } \\
\hline $\mathrm{S}$ & Insert shape $\left(90^{\circ}\right.$ point angle, square $)$ \\
$\mathrm{N}$ & Clearance angle $\left(0^{\circ}\right)$ \\
& \\
& Tolerance class \\
& {$[ \pm 0.002$ for inscribed circle $(\mathrm{d})$,} \\
$\mathrm{M}$ & \pm 0.003 for height of insert $(\mathrm{m})$, \\
& \pm 0.0005 for thickness $(\mathrm{s})]$ \\
& \\
& Insert features - number of \\
$\mathrm{G}$ & cutting edges with types of \\
& chip breaker geometry \\
& \\
04 & Cutting edge length $(12 \mathrm{~mm})$ \\
08 & Insert thickness $(4.76 \mathrm{~mm})$ \\
& Nose radius (0.8 mm $)$
\end{tabular}

and eco-friendly radiator coolant. Radiator coolant was chosen to be the base fluid as it is environmentally friendly and has abundant heat dissipation capability. The nanoparticle was procured from Sigma Aldrich. The size of the nanoparticle was less than $50 \mathrm{~nm}$. The coolant was manufactured by a German company, Wurth. For the preparation of nanofluid, the radiator coolant and distilled water were intermixed in the ratio of 1:4, initially. The requisite amount of $\mathrm{Al}_{2} \mathrm{O}_{3}$ nanoparticles i.e. (for $500 \mathrm{ml}$ solution, $2.5 \mathrm{gm}$. nanoparticle.) was further mixed with the base fluid. In order to improve the homogeneity of the mixture, a magnetic stirrer was used. The solution was kept on the magnetic stirrer for 5 hours then kept in an ultrasonicator for 2 hours, where the uniform colloidal solution was obtained. Figure 3 shows the set up for the present experimental investigation.

\section{Results and discussion}

\subsection{Study of chip morphology}

Chips are generally of two types:

1. Acceptable chips;

2. Unacceptable chips.

Acceptable chips do not interfere with the workpiece or machine tool and can be easily disposed. Unacceptable chips do not have such properties.

For the initial phase of the experimental investigation, compressed air was used as the working fluid and ribbon type chips were found. The chip color was found to be yellowish, as shown in Figure 4(a). This may be attributed to inadequate heat liberation. Hence, a negative impact on the workpiece and on the 


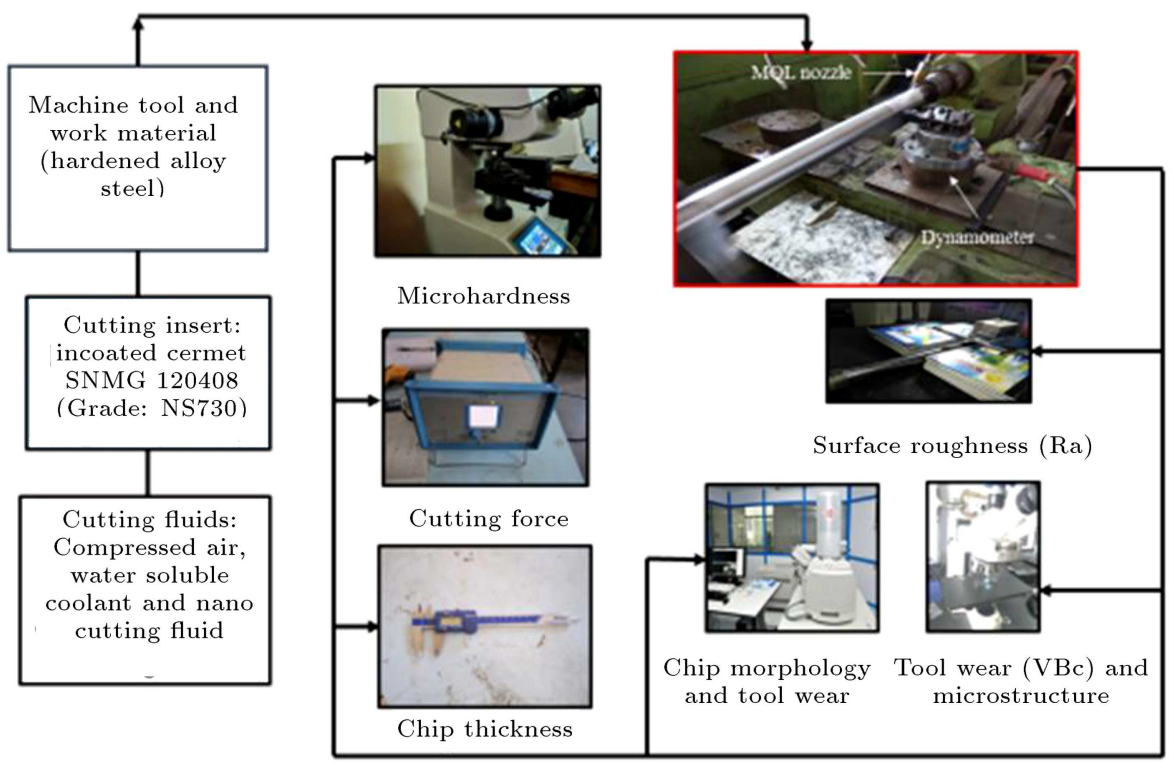

Figure 3. Experimental setup.

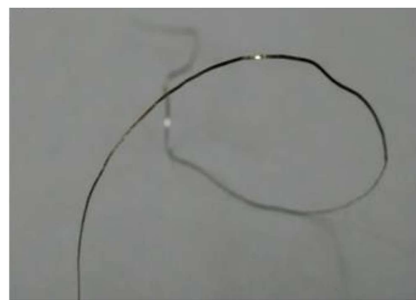

(a)

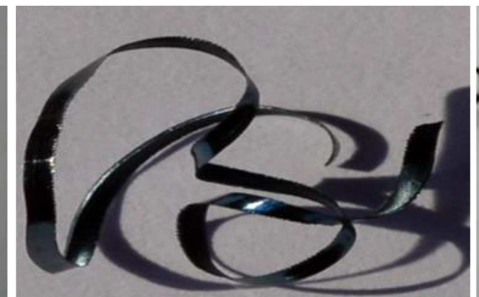

(b)

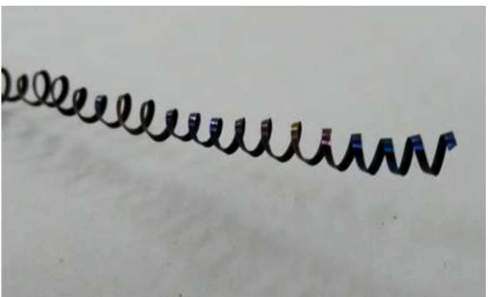

(c)

Figure 4. Chips produced using: (a) Compressed air, (b) water soluble coolant, and (c) nano cutting fluid.

tool was observed, especially in terms of surface finish and tool life. Water soluble coolant was used as the cutting fluid for the next phase of the experiment and it was found that long wavy chips of a blue color were formed, as shown in Figure 4(b). This might be because of the effective dissipation of heat rather than that of compressed air. The chips produced by the nano cutting fluid shown in Figure 4(c) were long, continuous and helical in nature. The helix angle of the chip was reduced by the use of aluminium oxide nanoparticles, as due to the impingement of the nanoparticles on the chips, more curled chips were formed. The blue color of the chips was a clear indication that the heat generated was properly liberated.

From Figure 5(a) illustrated above, distinctive white and black bands were observed known as ridges and feed marks, respectively. Ridges are formed at areas in high temperature generation zones and feed marks are formed at low temperature zones. Since high heat was generated with the use of compressed air and this heat was distributed non-uniformly over the chip surface, ridges and feed marks were more prominent. Prominent saw tooth was observed on the chip surface during compressed air machining. Shear localization

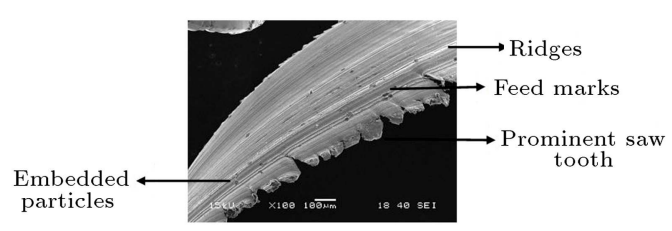

(a)

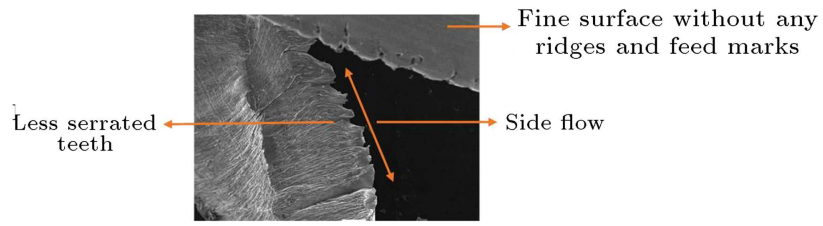

(b)

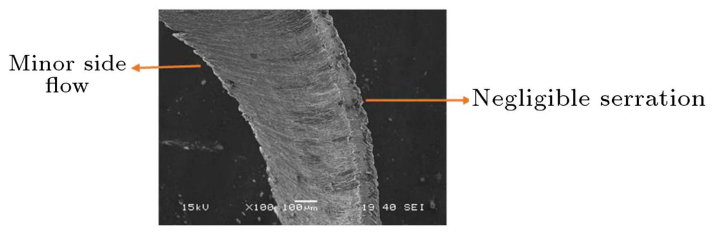

(c)

Figure 5. Scanning Electron Microscope (SEM) image of chip with (a) compressed air, (b) water soluble coolant, and (c) nano cutting fluid. 
and plastic deformation were two important factors in the formation of saw tooth during machining. As more friction was observed in compressed air machining, a high temperature resulted, which might be a reason for prominent saw tooth formation. There was a development of performance when water soluble coolant was used for the experiment. Side flow was observed in the chips and the serration was reduced appreciably in comparison to compressed air, and no ridges and feed marks were found. In this experimental work, less deformation occurred and machining became difficult due to the application of water soluble coolant, which is shown in Figure 5(b). This allowed the material to flow in a direction perpendicular to the feed leading to the material side flow. Negligible serrations and minor side flow were observed during the machining operation with nanofluid, as shown in Figure 5(c) because huge amount of heat was liberated in nanofluid compared to compressed air and water soluble coolant.

\subsection{Microhardness analysis}

One primitive aspect of machining activity is surface microhardness. The variation obtained in microhardness at the top surface of the machined specimen for three cutting fluids after a machining time of $240 \mathrm{~s}$, with three different speed levels i.e. 100, 120, and $140 \mathrm{~m} / \mathrm{min}$, was shown in Figure 6. It was shown that the microhardness profile obtained with nano cutting fluid was in between the use of compressed air and water soluble coolant for three ranges of cutting speeds. Its value was also reduced from the edge towards the center of the machined specimen. There was no substantial influence of water soluble coolant and nanofluid on microhardness alteration compared to compressed air. Further, a simplistic slope was noticed in the same diagram. This type of simplistic slope was observed due to the influence of the cutting zone temperature accompanied by the coolant application. At high speed i.e. $140 \mathrm{~m} / \mathrm{min}$, the surface temperature of the workpiece might be high due to insufficient heat transfer to the surroundings, because of less time. Hence, less microhardness was observed at the surface area compared to the sub surface region using water soluble coolant and nanofluid.

\subsection{Chip reduction coefficient or coefficient of chip contraction}

Chip length reduces, termed longitudinal chip contraction. Chip reduction coefficient or chip contraction coefficient is the ratio of chip thickness after and before cutting. It is also the inverse of the chip thickness ratio. It is the quantification of plastic deformation occurred during the machining process. It mainly depends upon the formation of Built Up Edge (BUE) and the amount of friction present at the tool-work and tool-chip interface [20]. It can be calculated by

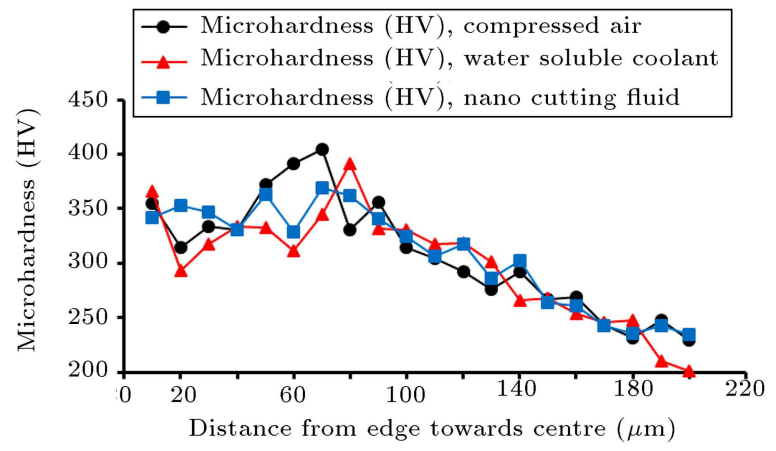

(b)

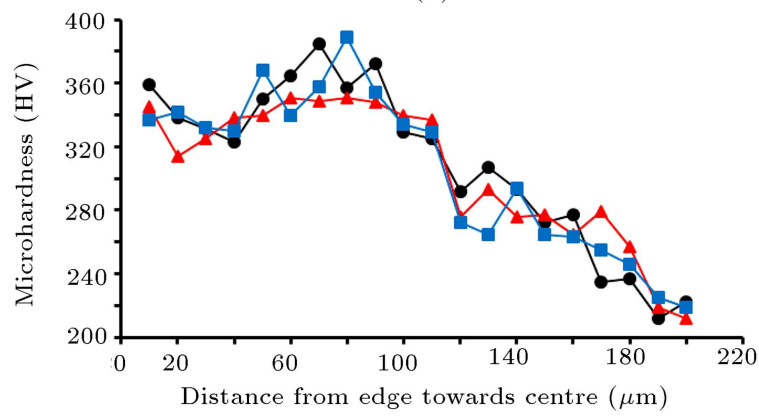

(a)

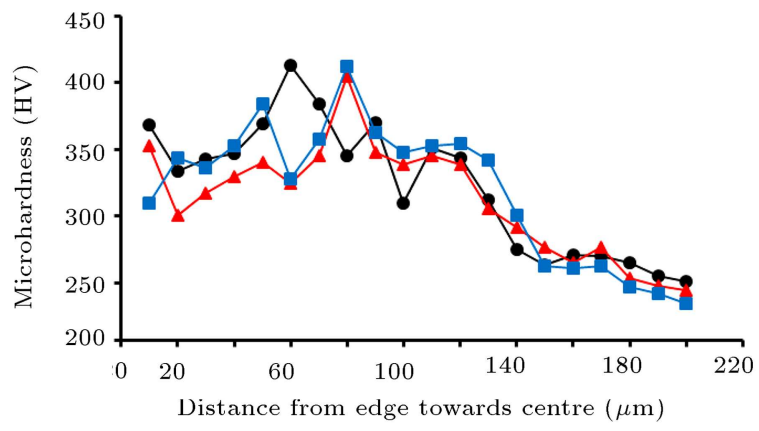

(c)

Figure 6. Variation of microhardness at cutting speed of (a) $100 \mathrm{~m} / \mathrm{min}$, (b) $120 \mathrm{~m} / \mathrm{min}$, and (c) $140 \mathrm{~m} / \mathrm{min}$.

the following formula:

$$
\xi=\frac{t_{c}}{t_{o}}
$$

where $t_{c}$ is the chip thickness and $t_{o}$ is the uncut chip thickness. The uncut chip thickness can be calculated by the following equation:

$$
t_{o}=f \cdot \sin \varphi
$$

where $\varphi$ is the approach angle of the insert. In the present experimental investigation $\varphi=75^{\circ}$ for SNMG or square shaped insert, and $f$ is the feed rate $(\mathrm{mm} / \mathrm{rev})$.

Figure 7 demonstrates the changes occurred in the chip reduction coefficient for three cutting fluids with different machining durations and cutting speeds. From the figure, it is concluded that a high chip reduction coefficient was found for compressed air 


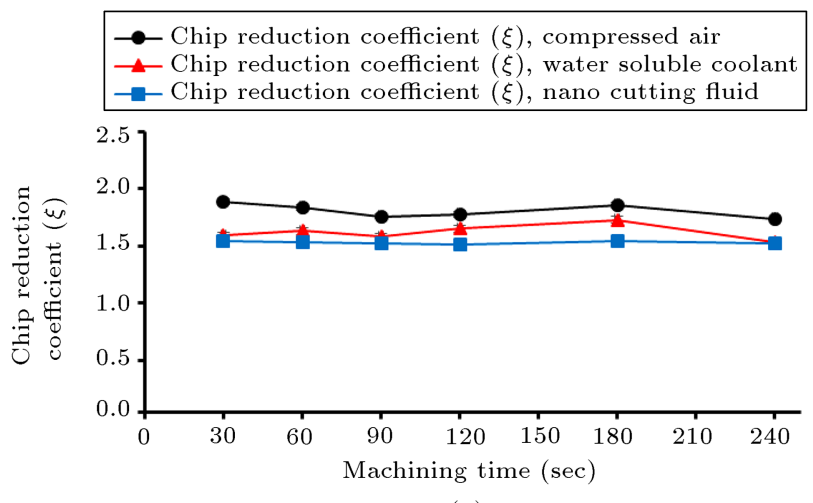

(a)

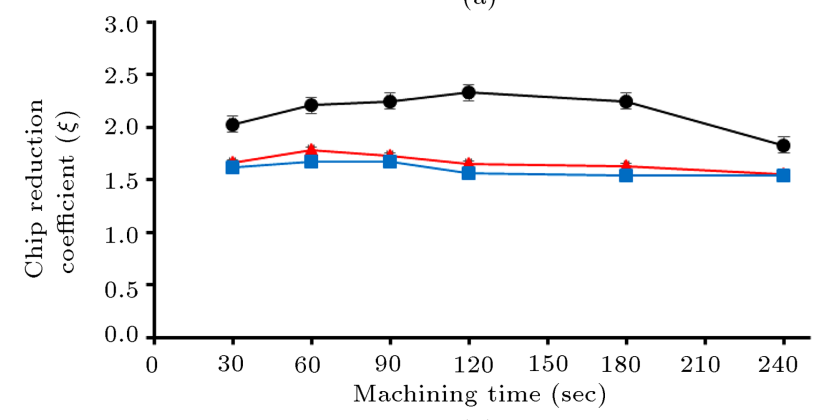

(b)

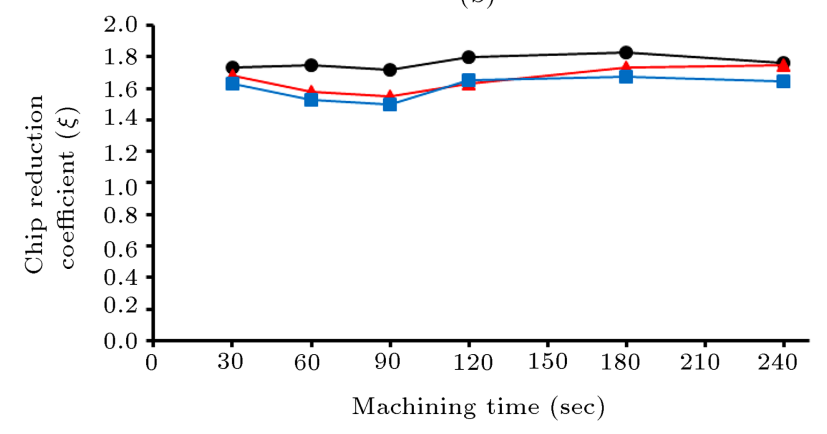

(c)

Figure 7. Comparison of chip reduction coefficient at (a) $100 \mathrm{~m} / \mathrm{min}$, (b) $120 \mathrm{~m} / \mathrm{min}$, and (c) $140 \mathrm{~m} / \mathrm{min}$.

compared to that found for water soluble coolant and nano-cutting fluid because of high friction. Minimum chip reduction coefficient was observed in the case of nanofluid owing to less friction.

\subsection{Apparent coefficient of friction}

Apparent coefficient of friction is a significant parameter for machining operations. It generally occurs at the interface of tool-work and tool-chip. It depends on tool wear and the machining environment. In the present experimental investigation, the apparent coefficient of friction for three cutting fluids, i.e. compressed air, water soluble coolant and nano cutting fluid, was calculated using the following formula:

$$
\mu=\frac{F_{c} \sin \Upsilon+F_{t} \cos \Upsilon}{F_{c} \cos \Upsilon-F_{t} \sin \Upsilon}
$$

where $\Upsilon$ is the orthogonal rake angle of the insert; $F_{c}$

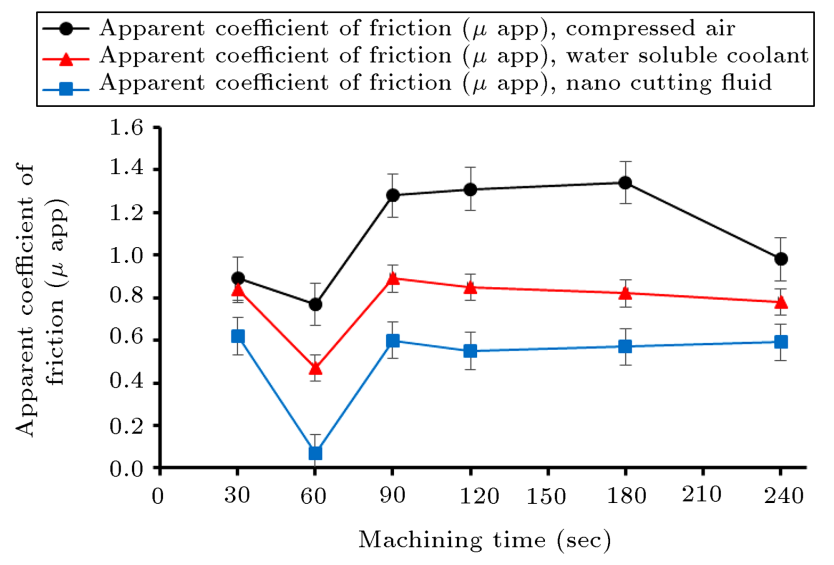

(a)

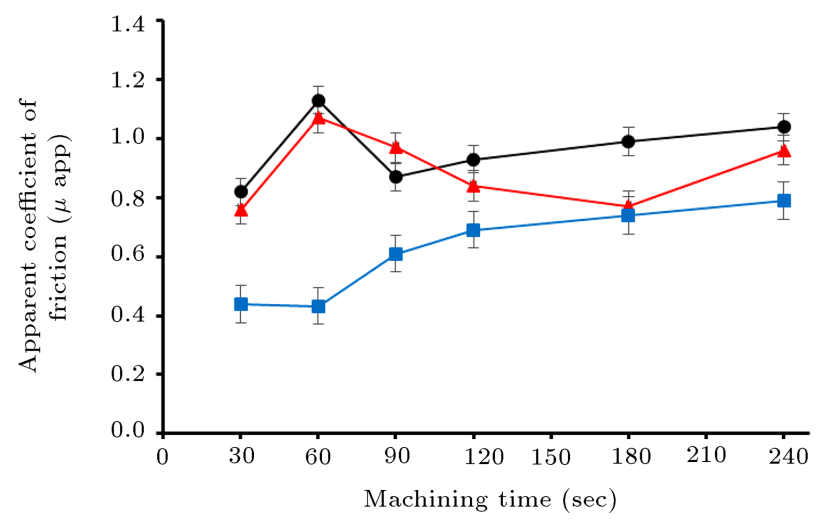

(b)

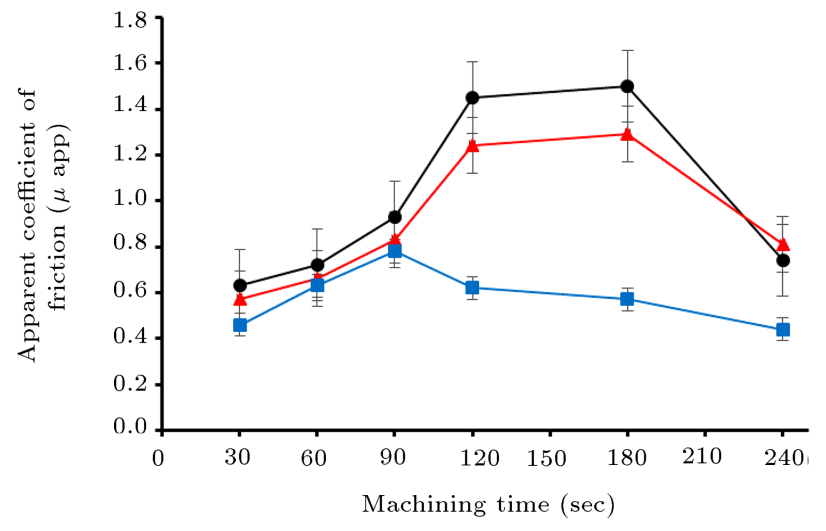

(c)

Figure 8. Variation of apparent coefficient of friction at: (a) $100 \mathrm{~m} / \mathrm{min}$, (b) $120 \mathrm{~m} / \mathrm{min}$, and (c) $140 \mathrm{~m} / \mathrm{min}$.

is the cutting force and $F_{t}$ is the thrust force; $F_{t}$ can be calculated by the following formula:

$$
F_{t}=\sqrt{F r^{2}+F_{f}^{2}}
$$

where $F_{r}$ is the radial force; and $F_{f}$ is the feed force.

Alteration of the apparent coefficient of friction with machining time for three cutting fluids at different speed levels is shown in Figure 8. From this figure, it was divulged that the apparent coefficient of friction was high for compressed air compared to water soluble 
coolant and nanofluid. The minimum value of the apparent coefficient of friction was obtained during application nanocoolant owing to its heat transfer capability. Temperature at the tool-work-chip interface resulted in a lesser magnitude of cutting force and friction.

\subsection{Analysis on main cutting force}

Cutting force is a significant primitive machinability aspect to be studied as it influences various other machining parameters such as power consumption, tool life, temperature, surface quality and chip quality etc. Figure 9 illustrates the variations present in the main cutting force with respect to machining time under application of three cutting fluids. From the figure, it is concluded that for a cutting speed of

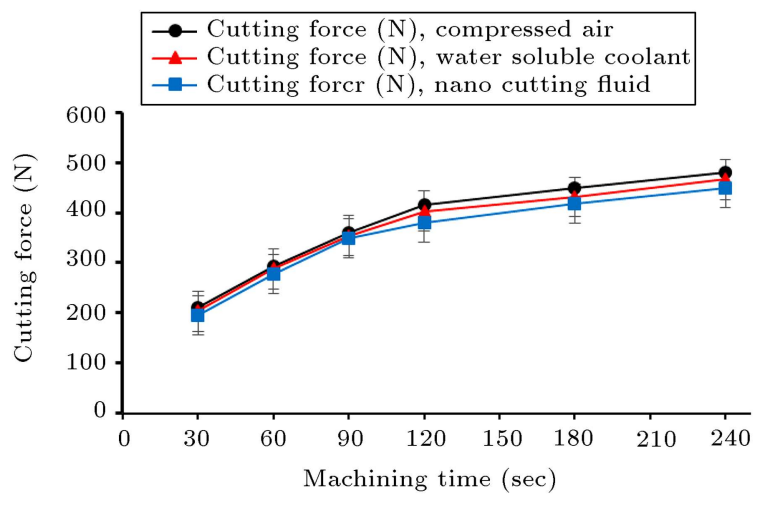

(a)

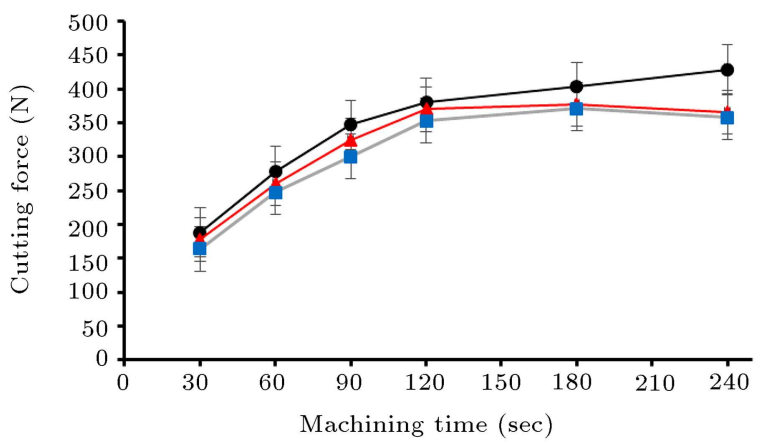

(b)

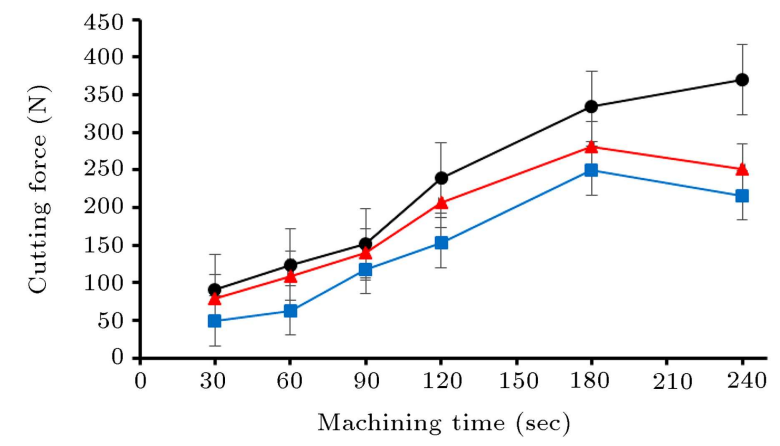

(c)

Figure 9. Main cutting force variation at: (a) $100 \mathrm{~m} / \mathrm{min}$, (b) $120 \mathrm{~m} / \mathrm{min}$, and (c) $140 \mathrm{~m} / \mathrm{min}$.
$100 \mathrm{~m} / \mathrm{min}$, there is a steady increment of the main cutting force with the machining time for three cutting fluids. However, when speed increased to $120 \mathrm{~m} / \mathrm{min}$ and $140 \mathrm{~m} / \mathrm{min}$, the main cutting force reduced slightly after $180 \mathrm{~s}$ machining time. Heat dissipation to the atmosphere is very difficult because of the shortened timespan at high cutting velocities that sometimes causes thermal softening of the workpiece. This might be a reason for the main cutting force reduction at high cutting speeds. Moreover, the shear strength of the workpiece reduces resulting shear deformation, at high cutting speeds, which affects the cutting force significantly. Greater magnitudes of main cutting force were observed with compressed air cooling for three different cutting speeds, while an opposite outcome was observed using nanofluid [21,22]. An interesting phenomenon was observed while applying nanofluid in the machining operation. There was a sharp abatement in main cutting force, approximately $55.05 \%$ and $25.55 \%$, with respect to compressed air and water soluble coolant. The credit goes to the excellent cooling and lubricating properties of the nanofluid and the rolling and cushioning effect of spherical shaped $\mathrm{Al}_{2} \mathrm{O}_{3}$ nanoparticles, which absorb any sudden load that lowers the cutting force. Similar observation is reported in the previous work [23]. There was no notable variation in the main cutting force between the application of water soluble coolant and nanofluid.

\subsection{Analysis on surface roughness}

Surface roughness $\left(R_{a}\right)$ was recorded after machining with three cutting fluids, exhibited in Figure 10. A higher degree of surface roughness was observed at $100 \mathrm{~m} / \mathrm{min}$ cutting speed. However, when altered to high range speeds, i.e. 120 and $140 \mathrm{~m} / \mathrm{min}$, magnitudes of surface roughness decreased slightly. From the figure, it was made clear that machining became smoother at relatively higher cutting velocities. At higher cutting speeds, thermal softening of the specimen work occurs, due to the fact that continuous machining resulted in less cutting force, which led to the achievement of finer surface quality. This might be the reason for getting less surface roughness at higher speeds. The chip characteristics highly influence surface quality. At higher cutting speeds, chip forms and breaks at the tool tip area with a slight plastic deformation which enhances surface quality. This might also be a reason for a superior surface finish at higher cutting speeds. Less surface roughness was observed for nanofluid [17,24] against water soluble coolant and compressed air for three different level of cutting speeds. This was due to the better cooling and lubrication aspects of nanoparticle based cutting fluid. Friction observed at tool-work and tool-chip interfaces was less and so roughness was found to be less due to these characteristics. More friction was observed 


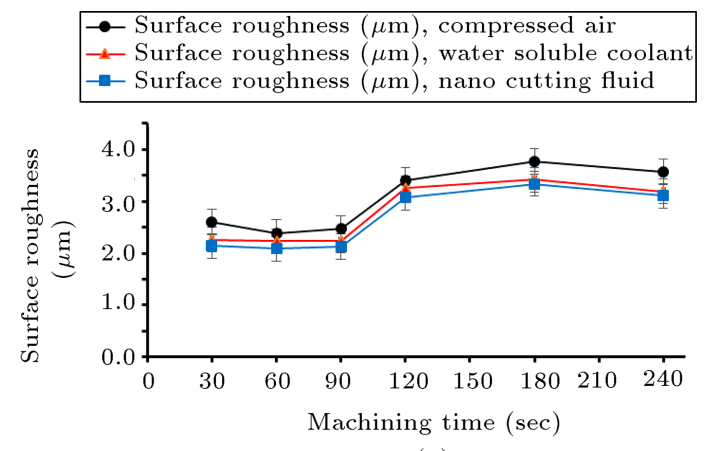

(a)

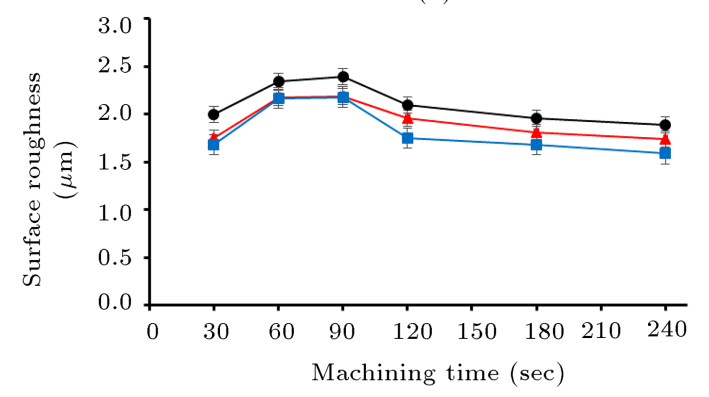

(b)

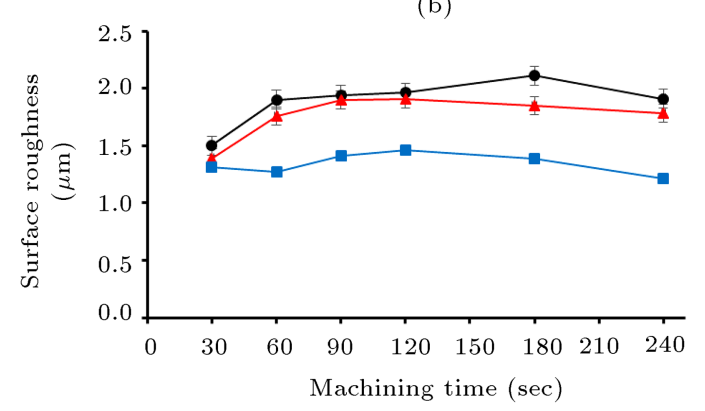

(c)

Figure 10. Surface roughness variation at: (a) $100 \mathrm{~m} / \mathrm{min}$, (b) $120 \mathrm{~m} / \mathrm{min}$, and (c) $140 \mathrm{~m} / \mathrm{min}$.

with compressed air. Owing to the inadequate heat dissipation of air, which resulted in improper cooling that led to a higher roughness value.

\subsection{Analysis of flank wear}

In the present research, flank wear on the inserts face was studied with the help of both SEM and an advanced optical microscope. Figure 11 displays the progress of average flank wear for different machining times at three different cutting speeds under three cutting fluid applications. A steep increment in wear at the flank surface was observed after $120 \mathrm{~s}$ of cutting time at a high range of cutting speeds, i.e. 120 and $140 \mathrm{~m} / \mathrm{min}$, particularly when the machining operation was performed with compressed air. However, no significant changes were observed in flank wear up to $60 \mathrm{~s}$ of machining time for three cutting speeds under three cutting fluid applications. Minimum wear on the flank face was observed in nanofluid machining due to its capability of effective cooling and lubrication [22].

The optical microscopic images demonstrated an

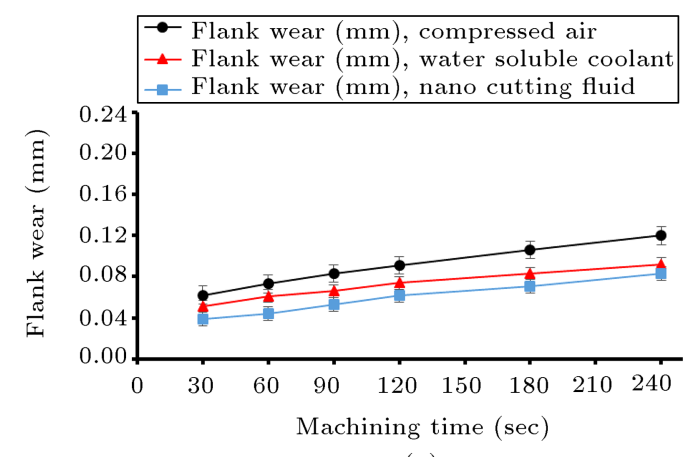

(a)

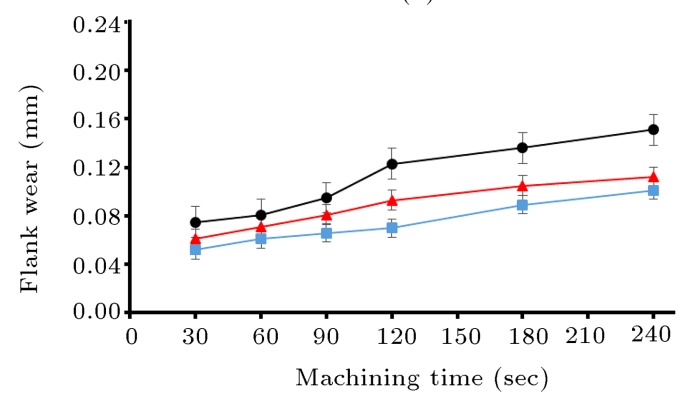

(b)

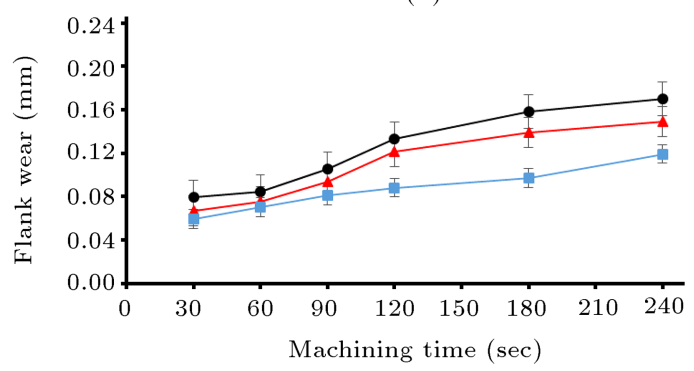

(c)

Figure 11. Flank wear variation at: (a) $100 \mathrm{~m} / \mathrm{min}$, (b) $120 \mathrm{~m} / \mathrm{min}$, and (c) $140 \mathrm{~m} / \mathrm{min}$.

advancement in flank wear for three different speeds with three dissimilar fluids, with respect to the duration of $240 \mathrm{~s}$ of machining, in Figure 12. At higher cutting speeds, i.e. $140 \mathrm{~m} / \mathrm{min}$, wear was found to be more for three cutting fluids. Similar results were visible for other machining time spans. Figure 13(a)(c) represents the SEM images of the flank faces of worn out inserts for three cutting fluids. As steel has a sticky nature, BUE was observed. BUE was observed as prominent with compressed air application. Much less BUE was visible while using water soluble coolant. BUE ceased to be formed using nanofluid. Similarly, rough abrasion marks and semi-rough abrasion marks were observed on the flank face when using compressed air and water soluble coolant. However, smooth abrasion was observed with nanofluid because of its excellent cooling and lubricating properties, which resulted in a sharp reduction of friction and temperature. It led to improve significantly in the cutting inserts performance, especially during the application of nanofluid under high speed machining. 


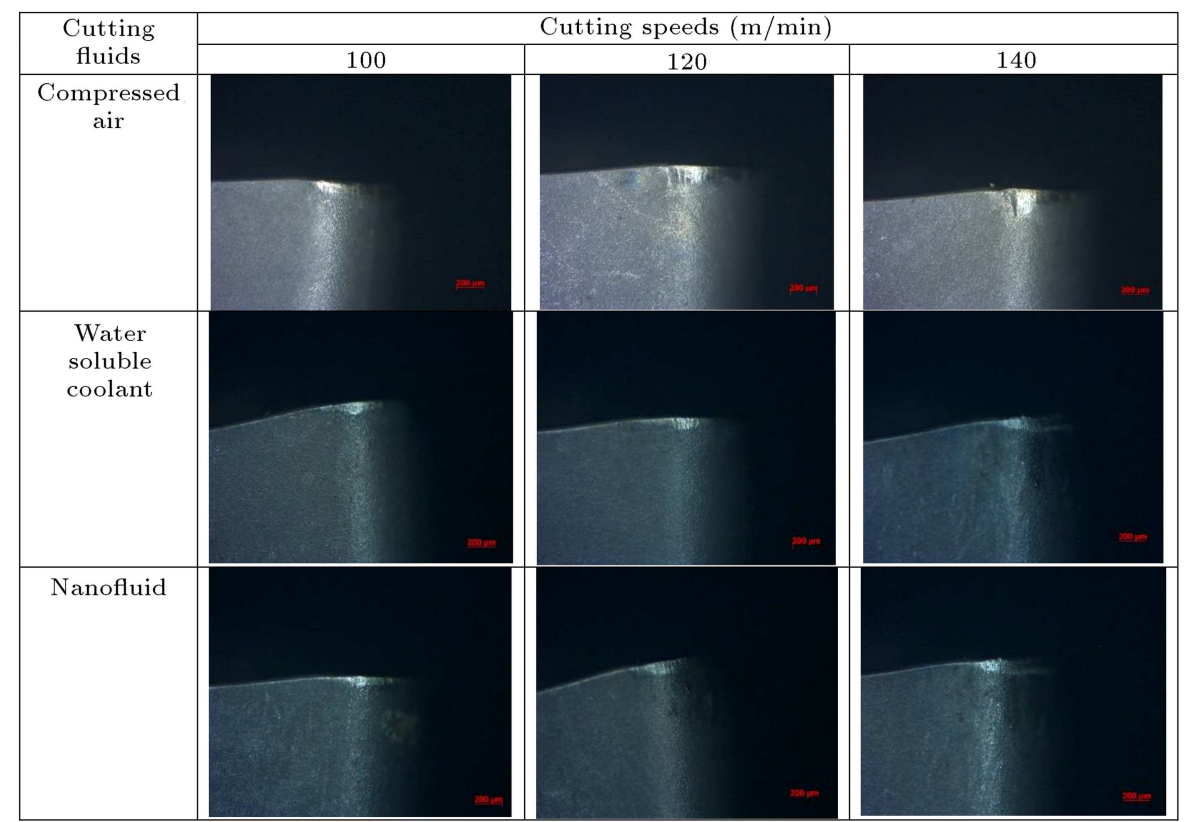

Figure 12. Flank wear at 100,120 , and $140 \mathrm{~m} / \mathrm{min}$ of cutting speed with compressed air, water soluble coolant and nanofluid application at $240 \mathrm{sec}$ of machining time.

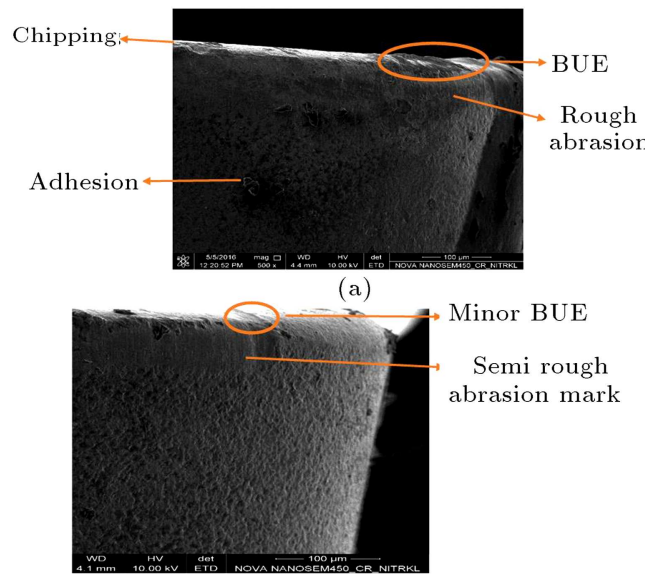

(b)

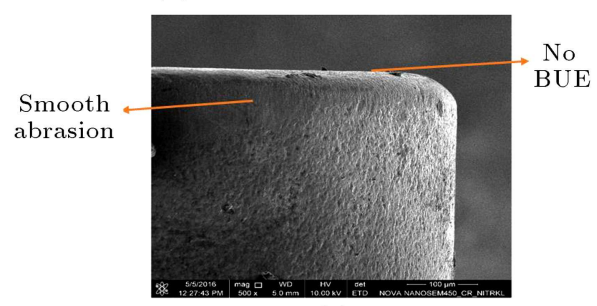

(c)

Figure 13. Scanning Electron Microscope (SEM) images of flank surface using: (a) Compressed air, (b) water soluble coolant, and (c) nano fluid at $140 \mathrm{~m} / \mathrm{min}$ speed.

\subsection{Crater wear analysis}

Rake face wear or crater wear, a primitive type of tool wear analysis, chiefly depends on the diffusion and adhesion wear. High temperature, pressure and the chemical affinity of the test specimen are the three dominating parameters for such wear. Figure 14 demonstrated the optical microscopic images of the rake faces of inserts for compressed air, water soluble coolant and nano cutting fluid at three speed levels, with respect to $240 \mathrm{~s}$ machining time. From Figure 14, it is made clear that rake faces of the inserts were damaged because of catastrophic failure in the compressed air machining environment rather than that of water soluble coolant and nanofluid machining. At the speed level of $140 \mathrm{~m} / \mathrm{min}$, more wear was observed for all three cutting fluids. Similar results were observed for other machining times. Abrasion, adhesion, plastic deformation and BUE formation were the four major wear mechanisms found to fit the crater wear analysis in the current research. Adhesion was the most sound wear mechanism for three cutting fluids. The higher chemical affinity of the test specimen might be a reason for this adhesion as it has a sticky nature. From the SEM images of the rake surfaces shown in Figure 15 for three cutting fluids, it is observed that thin abrasion, adhering layer and BUE were present in water soluble coolant machining. Thick abrasion marks, prominent adhering layers and plastic deformation were present with compressed air machining, whereas a very thin layer due to adhesion was present. No plastic deformation, BUE or abrasion were observed while machining with nanofluid. This showed the superior functional capability of nanofluid and its advantage over compressed air and water soluble coolant.

\subsection{Analysis of machined surface morphology} Machined surface morphology is a prominent aspect of a machining operation, normally characterized by the macro morphology of machined part. Figure 16 


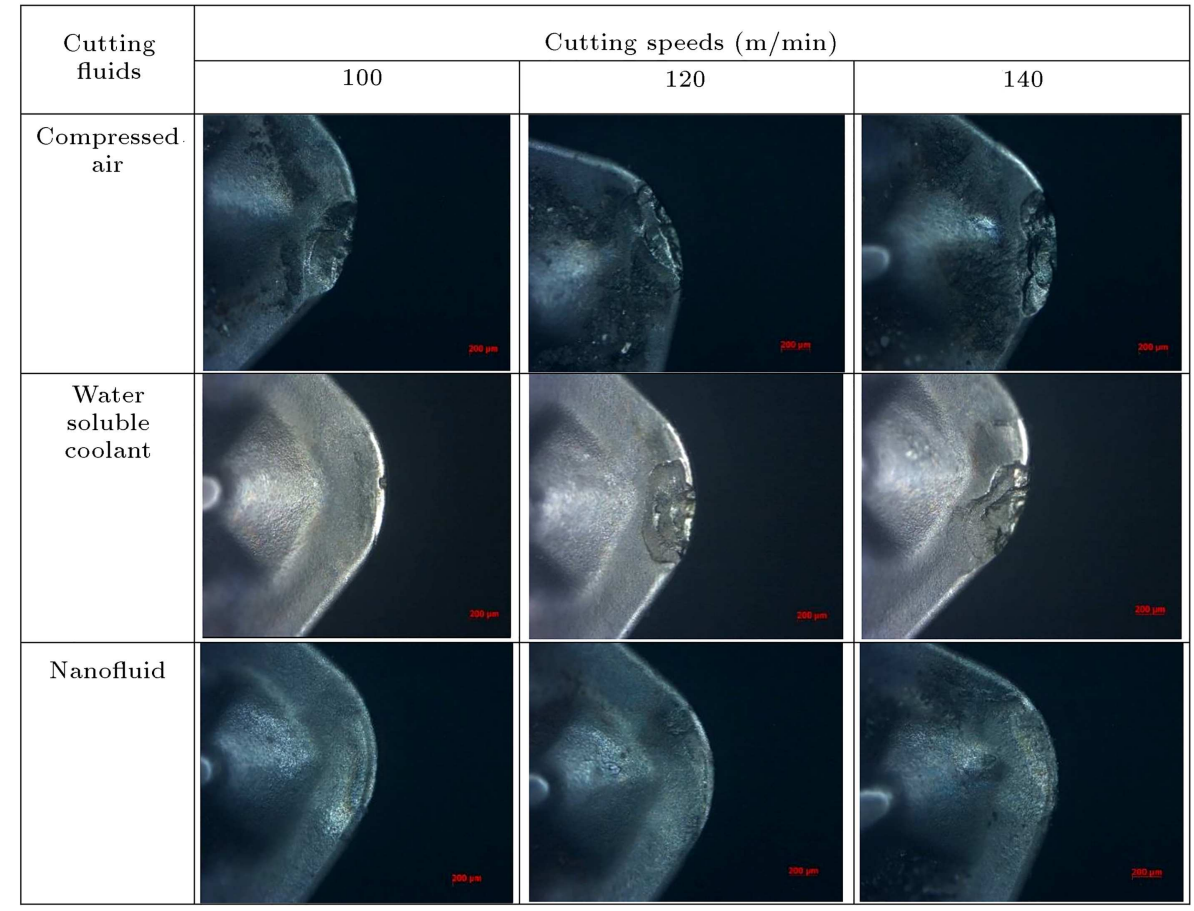

Figure 14. Wear on rake face at 100, 120 and $140 \mathrm{~m} / \mathrm{min}$ of cutting speed with compressed air, water soluble coolant and nanofluid application at $240 \mathrm{~s}$ of machining time.

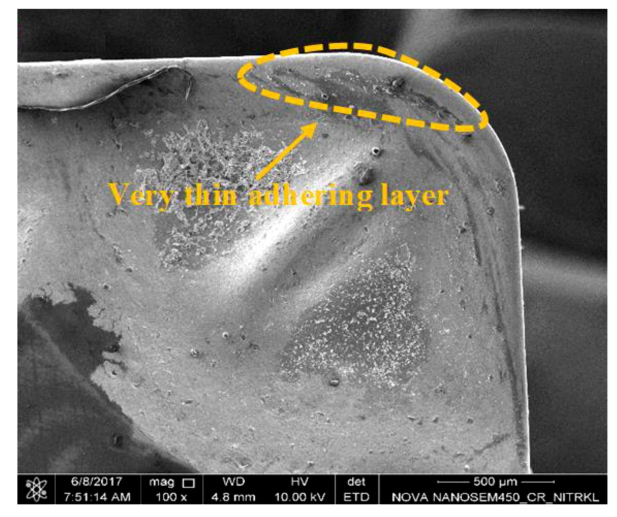

(a)

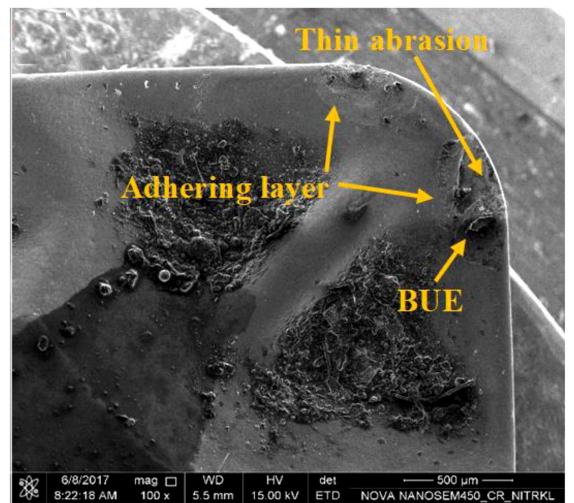

(b)

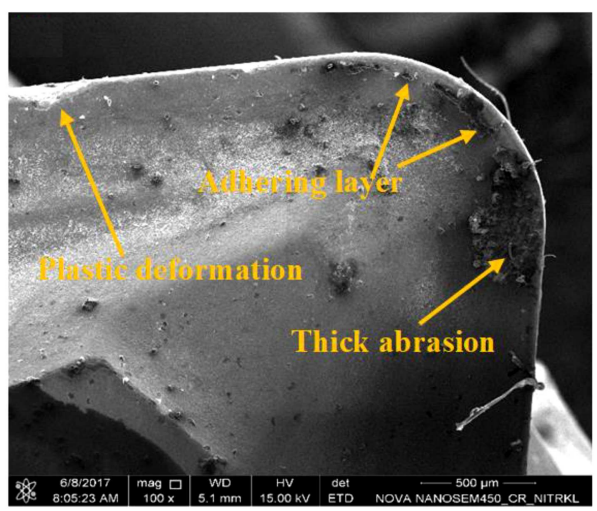

(c)

Figure 15. Scanning Electron Microscope (SEM) images of rake surface using: (a) Nano cutting fluid, (b) water soluble coolant, and (c) compressed air at $140 \mathrm{~m} / \mathrm{min}$ speed. 


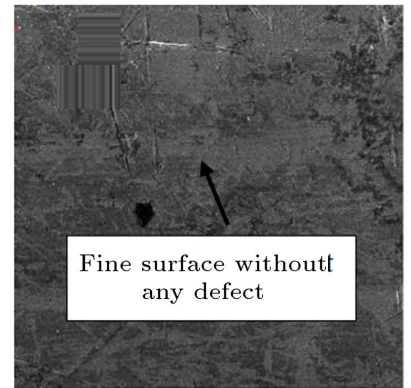

(a)

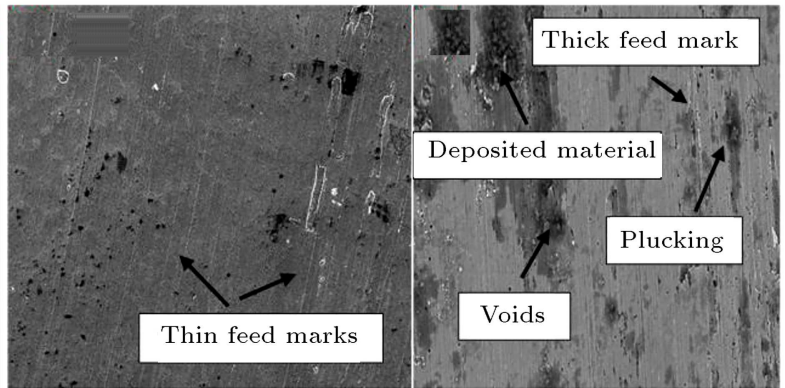

(b)

(c)

Figure 16. Scanning Electron Microscope (SEM) images of machined surface morphology using: (a) Nano cutting fluid, (b) water soluble coolant, and (c) compressed air at $140 \mathrm{~m} / \mathrm{min}$ speed.

illustrated the machined surface morphology using uncoated cermet inserts for three cutting fluids at $140 \mathrm{~m} / \mathrm{min}$ cutting speed. Feed marks, void, plucking and deposited material were found on the machined surface with compressed air machining. Thin feed marks were observed when machining with water soluble coolant. For nanofluid machining, no surface defects were found, while more damage was observed when using compressed air due to inappropriate cooling and lubricating characteristics. The high surface temperature of the workpiece, more tool wear and severe plastic flow are the reasons for the damage on the machined surface. The high surface temperature of the workpiece resulted in plastic deformation, which led to the adhesion of chips onto the machined surface.

\section{Conclusions}

Every experiment conducted achieved a certain set of goals. The set of conclusions drawn represents the front-end of the genuine research executed, and are listed below:

- A large degree of deterioration in principal cutting force i.e., $55.05 \%$ and $25.55 \%$ was observed when machining with AISI 4340 hardened alloy steel with the application of nanofluid in comparison to that of compressed air and water soluble coolant cutting conditions;

- A steep reduction of $78 \%$ and $49.04 \%$ in the context of flank wear was observed by nanofluid application as compared to compressed air and water soluble coolant;

- Superior surface finish and better surface quality were observed with nanofluid machining compared to compressed air and water soluble coolant machining;

- Water soluble coolant based Minimum Quantity Lubrication (MQL) and compressed air cutting environments affect the microhardness of the machined part adversely at surface and sub-surface regions, but the nanofluid based MQL treatment has not done so;

- Nanofluid can be successfully implemented as a metal working fluid during the machining of hardened AISI 4340 grade alloy steel to get the desired machining characteristics within a specified range of cutting parameters;

- An ecofriendly radiator coolant can be now utilized as a base fluid for nano-coolant preparation and is compatible with the environment.

\section{Nomenclature}

$\begin{array}{ll}\text { AISI } & \text { American Iron and Steel Institute } \\ d & \text { Depth of cut }(\mathrm{mm}) \\ \text { Eq. } & \text { Equation } \\ f & \text { Feed (mm/rev) } \\ F_{c} & \text { Resultant cutting force }(\mathrm{N}) \\ F_{f} & \text { Feed force }(\mathrm{N}) \\ F_{r} & \text { Radial force }(\mathrm{N}) \\ F_{t} & \text { Thrust force }(\mathrm{N}) \\ \text { HRC } & \text { Rockwell Hardness in C scale } \\ \text { MQL } & \text { Minimum Quantity Lubrication } \\ r & \text { Nose radius (mm) } \\ \text { SEM } & \text { Scanning Electron Microscope } \\ v & \text { Cutting speed (m/min) } \\ V B c & \text { Flank wear of inserts (mm) } \\ \lambda_{o} & \text { Rake angle (degree) }\end{array}$

\section{References}

1. Rao, R.V. and Kalyankar, V.D. "Multi-pass turning process parameter optimization using teachinglearning-based optimization algorithm", Scientia Iranica, E, 20(3), pp. 967-974 (2013).

2. Shen, B., Shih, A.J., and Tung, S.C. "Application of nanofluids in minimum quantity lubrication grinding", Tribology Transactions, 51(6), pp. 730-737 (2008). 
3. Hegab, H., Umer, U., Soliman, M., and Kishawy, H.A. "Effects of nano-cutting fluids on tool performance and chip morphology during machining Inconel 718", The International Journal of Advanced Manufacturing Technology, 96(9-12), pp. 3449-3458 (2018).

4. Kuzu, A.T., Bijanzad, A., and Bakkal, M. "Experimental investigations of machinability in the turning of compacted graphite iron using minimum quantity lubrication", Machining Science and Technology, 19(4), pp. 559-576 (2015).

5. Amini, S., Khakbaz, H., and Barani, A. "Improvement of near-dry machining and its effect on tool wear in turning of AISI 4142", Materials and Manufacturing Processes, 30(2), pp. 241-247 (2014).

6. Kumar, R., Sahoo, A.K., Mishra, P.C., and Das, R.K. "Measurement and machinability study under environmentally conscious spray impingement cooling assisted machining", Measurement, 135, pp. 913-927 (2019).

7. Mia, M., Gupta, M.K., Singh, G., Królczyk, G., and Pimenov, D.Y. "An approach to cleaner production for machining hardened steel using different coolinglubrication conditions", Journal of Cleaner Production, 187, pp. 1069-1081 (2018).

8. Mia, M., Rifat, A., Tanvir, M.F., Gupta, M.K., Hossain, M.J., and Goswami, A. "Multi-objective optimization of chip-tool interaction parameters using Grey-Taguchi method in MQL-assisted turning", Measurement, 129, pp. 156-166 (2018).

9. Mia, M., Morshed, M.S., Kharshiduzzaman, M., Razi, M.H., Mostafa, M.R., Rahman, S.M.S., Ahmada, I., Hafiz, M.T., and Kamal, A.M. "Prediction and optimization of surface roughness in minimum quantity coolant lubrication applied turning of high hardness steel", Measurement, 118, pp. 43-51 (2018).

10. Nemati, H., Farhadi, M., Sedighi, K., Ashorynejad, H.R., and Fattahi, E. "Magnetic field effects on natural convection flow of nanofluid in a rectangular cavity using the lattice Boltzmann model", Scientia Iranica, 19(2), pp. 303-310 (2012).

11. Amrita, M., Srikant, R.R., and Sitaramaraju, A.V. "Performance evaluation of nanographite-based cutting fluid in machining process", Materials and Manufacturing Processes, 29(5), pp. 600-605 (2014).

12. Sharma, A.K., Tiwari, A.K., and Dixit, A.R. "Progress of nanofluid application in machining: A review", Materials and Manufacturing Processes, 30(7), pp. 813-828 (2014).

13. Sharma, P., Sidhu, B.S., and Sharma, J. "Investigation of effects of nanofluids on turning of AISI D2 steel using minimum quantity lubrication", Journal of Cleaner Production, 108, pp. 72-79 (2015).

14. Su, Y., Gong, L., Li, B., Liu, Z., and Chen, D. "Performance evaluation of nanofluid MQL with vegetablebased oil and ester oil as base fluids in turning", The International Journal of Advanced Manufacturing Technology, 83(9-12), pp. 2083-2089 (2015).
15. Patole, P.B. and Kulkarni, V.V. "Experimental investigation and optimization of cutting parameters with multi response characteristics in MQL turning of AISI 4340 using nano fluid", Cogent Engineering, 4(1), pp. 1-14 (2017).

16. Khajehzadeh, M., Moradpour, J., and Razfar, M.R. "Influence of nanofluids application on contact length during hard turning", Materials and Manufacturing Processes, 34(1), pp. 30-38 (2019).

17. Amrita, M., Shariq, S.A., Manoj, and Gopal, C. "Experimental investigation on application of emulsifier oil based nano cutting fluids in metal cutting process", Procedia Engineering, 97, pp. 115-124 (2014).

18. Sharma, A.K., Singh, R.K., Dixit, A.R., and Tiwari, A.K. "Novel uses of alumina-MoS ${ }_{2}$ hybrid nanoparticle enriched cutting fluid in hard turning of AISI 304 steel", Journal of Manufacturing Processes, 30, pp. 467-482 (2017).

19. Singh, R.K., Sharma, A.K., Dixit, A.R., Tiwari, A.K., Pramanik, A., and Mandal, A. "Performance evaluation of alumina-graphene hybrid nano-cutting fluid in hard turning", Journal of Cleaner Production, 162, pp. 830-845 (2017).

20. Kumar, R., Sahoo, A.K., Mishra, P.C., and Das, R.K. "Comparative investigation towards machinability improvement in hard turning using coated and uncoated carbide inserts: Part I: Experimental investigation", Advances in Manufacturing, 6(1), pp. 52-70 (2018).

21. Rahmati, B., Sarhan, A.A.D., and Sayuti, M. "Investigating the optimum molybdenum disulfide $\left(\mathrm{MoS}_{2}\right)$ nanolubrication parameters in CNC milling of AL6061T6 alloy", The International Journal of Advanced Manufacturing Technology, 70(5-8), pp. 1143-1155 (2013).

22. Saravanakumar, N., Prabu, L., Karthik, M., and Rajamanickam, A. "Experimental analysis on cutting fluid dispersed with silver nano particles", Journal of Mechanical Science and Technology, 28(2), pp. 645651 (2014).

23. Das, S.R., Panda, A., and Dhupal, D. "Experimental investigation of surface roughness, flank wear, chip morphology and cost estimation during machining of hardened AISI 4340 steel with coated carbide insert", Mechanics of Advanced Materials and Modern Processes, 3(1), pp. 1-14 (2017).

24. Khalilpourazary, S. and Meshkat, S.S. "Investigation of the effects of alumina nanoparticles on spur gear surface roughness and hob tool wear in hobbing process", The International Journal of Advanced Manufacturing Technology, 71(9-12), pp. 1599-1610 (2014).

\section{Biographies}

Anshuman Das is at present a Research Scholar in the Industrial Design Department of the National Institute of Technology, Rourkela. He graduated in Mechanical Engineering from Biju Patnaik University 
of Technology, Rourkela in 2007. He obtained a MTech degree from the National Institute of Technology, Jamshedpur with a specialization in "Design \& Manufacturing". His research interests include hard machining, machining process modelling, optimization, analysis and prediction, cryo treatment of cutting inserts and nanofluid applications in the machining of hard materials.

Saroj Kumar Patel is at present Professor in the Mechanical Engineering Department of the National institute of Technology, Rourkela. He graduated in Mechanical Engineering from the National Institute of Technology, Rourkela in 1985. Initially, he served with Hindustan Aeronautics Limited, Koraput Division, Sunabeda. He obtained an MTech degree from the Indian Institute of Technology Madras, Chennai and a PhD degree from the Indian Institute of Technology Kharagpur. His research interests include optimization and quality control.

Bibhuti Bhusan Biswal was born in Rourkela, Odisha, India in 1962. He received a BE degree in Mechanical Engineering from UCE, Burla, India in 1985. Subsequently, he completed his MTech, and PhD from Jadavpur University, Kolkata. He was a faculty member of the Mechanical Engineering Dept. at UCE Burla from 1986 till 2004 and then joined the National Institute of Technology, Rourkela as Professor. He is currently Professor in the Department of Industrial Design and the Dean (Faculty Welfare) of NIT, Rourkela. He has been actively involved in various research projects and published more than 110 papers at National and International levels including a monogram on Management Information Systems for ISTE, New Delhi. He has written 6 book chapters and has more than 3 patents. His research interests include Robotics, FMS, CAD/CAM, Mechatronics, CIM, AMT, Virtual Manufacturing, and Production Management. Dr. Biswal is a member of IE (I: Fellow), ASME (Member), IEEE (Senior Member), ISTE (Life Member), Association for Machines and Mechanisms (AMM: Life Member), ISTAM (Member), International Association of Computer Science and Information Technology (IACSIT: Member) and International Association of Engineers (IAENG: Member). He was the Keynote speaker of ICACC, 2009 (IEEE Conference), Singapore, ICCET, 2009 (IEEE Conference), Singapore, ICROM, 2014 (IACSIT).

Sudhansu Ranjan Das is currently Associate Professor in the Department of Production Engineering, Veer Surendra Sai University of Technology (VSSUT), Burla, India. He received his $\mathrm{PhD}$ in Manufacturing Engineering in 2016 from the National Institute of Technology, Jamshedpur, India. His research interests include hard machining, machining process modelling, optimization, analysis and prediction. He has published more than 31 papers in refereed journals and conference proceedings. 